\title{
Putting It Together: Finding Success in Behavior Change Through Integration of Services
}

Steven $H$. Woolf, $M D, M P H^{1}$

Russell E. Glasgow, $\mathrm{PbD}^{2}$

Alex Krist, $M D^{1}$

Claudia Bartz, PbD, RN ${ }^{3}$

Susan A. Flocke, PbD

Jodi Summers Holtrop, PbD, CHES

Stephen F. Rothemich, $M D, M S^{1}$

Ellen R. Wald, $M D^{6}$

${ }^{1}$ Department of Family Medicine, Virginia Commonwealth University, Richmond, Va

${ }^{2}$ Kaiser Permanente Colorado, Denver, Colo

${ }^{3}$ University of Wisconsin Milwaukee College of Nursing, Milwaukee, Wis

${ }^{4}$ Case Western Reserve University, Cleveland, Ohio

${ }^{5}$ Department of Family Practice, Michigan State University, East Lansing, Mich

${ }^{6}$ Children's Hospital of Pittsburgh, University of Pittsburgh School of Medicine, Pittsburgh, $\mathrm{Pa}$

Conflicts of interest: none reported

\section{CORRESPONDING AUTHOR}

Steven H. Woolf, MD, MPH Department of Family Medicine

Virginia Commonwealth University

3712 Charles Stewart Dr

Fairfax, VA 22033

swoolf@vcu.edu

\begin{abstract}
PURPOSE The purpose of this analysis and commentary was to explore the rationale for an integrated approach, within and outside the office, to help patients pursue healthy behaviors.
\end{abstract}

METHODS We examined the role of integration, building on (1) patterns observed in a limited qualitative evaluation of 17 Prescription for Health projects, (2) several national policy initiatives, and (3) selected research literature on behavior change.

RESULTS The interventions evaluated in Prescription for Health not only identified unhealthy behaviors and advised change, but also enabled patients to access information at home, use self-help methods, obtain intensive counseling, and receive follow-up. Few practices can replicate such a model with the limited staff and resources available in their offices. Comprehensive assistance can be offered to patients, however, by integrating what is feasible in the office with additional services available through the community and information media.

CONCLUSIONS Blending diverse clinical and community services into a cohesive system requires an infrastructure that fosters integration. Such a system provides the comprehensive model on which the quality of both health promotion and chronic illness care depend. Integrating clinical and community services is only the first step toward the ideal of a citizen-centered approach, in which diverse sectors within the community - health care among them-work together to help citizens sustain healthy behaviors. The integration required to fulfill this ideal faces logistical challenges but may be the best way for a fragmented health care system to fully serve its patients.

Ann Fam Med 2005;3(Suppl 2):S20-S27. DOI: 10.1370/afm.367.

\section{INTRODUCTION}

A ddressing health behaviors in primary care involves a familiar sequence of steps: (1) identifying the behavior(s) in question, (2) giving brief advice, (3) setting goals, (4) arranging for more intensive assistance, and (5) ensuring follow-up. ${ }^{1}$ This sequence of tasks is embodied in a variety of models for behavioral counseling, notably the 5 A's — assess (ask about the behavior status and the factors affecting change), advise (give a clear, personal message of encouragement to change), agree (set goals based on readiness to change), assist (use behavior change techniques, such as self-help, counseling, or both, to promote acquisition of the skills, confidence, and environmental supports for change, supplemented by medical treatments when appropriate), and arrange (schedule follow-up contacts, including referral for more intensive treatment). ${ }^{2}$

The effectiveness of clinicians in promoting healthy behaviors and the quality of their service to patients are probably maximized when practices have systems in place to support this entire counseling sequence-all of the 5 A's — rather than simply components of the process. ${ }^{3}$ Systematic reviews and clinical experience have shown that practices that use multifaceted inter- 
ventions are more effective in promoting healthy behaviors than those that institute isolated measures. ${ }^{1,4-6}$

How might such a comprehensive system look in conventional primary care practices? In a perfect world, it would include a redesigned system of office practice that would enable clinicians to offer the full range of services, aided by trained counselors and information technology and adequately reimbursed by payers. Such an idealized office design, as envisioned by the Future of Family Medicine project, ${ }^{7}$ would be part of an overall restructuring of the health care system that experts now consider vital. ${ }^{8}$ Until that restructuring occurs, however, strategies to promote health behavior change must be pragmatic. The model must be realistic and compatible with the competing demands of today's practice environment, minimizing intrusion on the productivity of clinicians and their limited time.

We sought insight into this issue by performing a limited qualitative evaluation of the interventions tested in the first round of the Robert Wood Johnson Foundation's Prescription for Health program. As described in more detail by Cifuentes et $\mathrm{al}^{9}$ and others in this supplement, this program provided funding to 17 primary care practice-based research networks to test interventions for unhealthy behaviors (smoking, unhealthy diet, physical inactivity, and risky alcohol use) among patients in their practices. In this commentary, we use our analysis of these projects as a point of departure for examining larger lessons about the role of integrated services, both in primary care and in the community at large, in promoting healthy behaviors.

\section{METHODS}

We reviewed original proposals and interim reports from each of the 17 Prescription for Health grantees, and classified each intervention within the $5 \mathrm{~A}$ 's framework (Table 1). Each grantee verified that our list included all interventions evaluated in their project, and approved the 5 A's classification assigned to each intervention. We also examined themes shared by the investigators at grantee meetings convened by the foundation and themes identified in evaluations sponsored by the foundation. ${ }^{4}$ Finally, using a focused literature review, we examined the concordance between these themes and the attributes of integration that figure prominently in research and national policy initiatives.

\section{RESULTS}

Insights From Prescription for Health: Integration of Services to Achieve Comprehensive Care

Our review of the Prescription for Health projects

found that pragmatic features were common among the interventions tested, an outcome reflective of the pro- gram's design. The original call for proposals from the foundation specified that applicants test interventions that could be "easily adopted" and complete their projects within 16 months; project grants could not exceed $\$ 125,000$. These constraints precluded the testing of complex or protracted interventions, and fostered innovation among grantees to fashion interventions that ordinary practices could implement.

Few Prescription for Health projects were able to evaluate a comprehensive system for promoting behavior change. The interventions instead addressed selected components of the 5 stages of counseling (Table 1). Some interventions screened for unhealthy behavior, some changed the way advice was given, some focused on goal setting, and some provided more intensive assistance. In only 4 projects did the interventions address all of the 5 A's.

Although no Prescription for Health project was totally comprehensive, when the projects' interventions are examined as a whole, the design of a complete system to fully support behavior change takes form. A synthesis of the projects (Figure 1) presents a vision for an integrated, multifaceted system with realistic potential for implementation in primary care settings Practices that wish to support each of the 5 A's can choose from the menu of options in the figure, tested by the grantees, to (1) identify unhealthy behaviors (eg, by health risk appraisals), (2) offer brief advice, (3) set collaborative goals and action plans (eg, behavior "prescriptions"), (4) provide more extensive information (eg, handouts, interactive Web sites), counseling (eg, inoffice coaches or community health advisors, telephone counseling, group didactic sessions, and support groups, some using motivational interviewing), and self-help tools (eg, guidebooks, pedometers, activity logs, food diaries), and (5) arrange follow-up and reinforcement (eg, health buddies, e-mail or telephone follow-up).

Other strategies not tested under Prescription for Health offer additional options for supporting behavior change. Examples include computer-generated physician and patient reminders and e-mails, chart reminder stickers and flow sheets, examination and waiting room posters, teamwork interventions, patient-held health diaries, and interactive technologies (eg, Web-based resources, clinic-based CD-ROMs, interactive voiceresponse telephone calls). ${ }^{10,11}$

\section{Integration Between the Practice and the Community: Reaching Out Beyond the Clinic}

Intensive counseling can enhance behavior change but is often beyond the capacity of ordinary primary care practices, which lack the time and resources for such follow-up. As Cohen et $\mathrm{al}^{4}$ describe in this supplement, Prescription for Health grantees discovered that deliver- 
ing high-quality counseling often taxed the capabilities of practices and their staff. Some interventions required clinicians to undergo extensive training or to depend on practice extenders and external support from research teams. The long-term sustainability of such self-contained interventions is unclear ${ }^{4,12}$; furthermore, their generalizability to practices across the country is uncertain.

Real-world practices that lack the resources to replicate intensive approaches within their offices can still ensure that patients receive high-quality counseling by reaching out beyond the office-establishing integrated linkages with information and community resources. The few minutes that clinicians and staff have with patients can then be used for what clinicians do best: identifying the behaviors and conveying to patients the importance of change. ${ }^{13,14}$ As Stange et al ${ }^{15}$ have advocated, these first steps can be leveraged into more effective interventions if they connect patients with professionals and programswithin or outside the office- - that can provide more extensive followup. As with any consulting relationship, these resources should work in concert with primary care professionals in a team approach, reporting to and consulting with clinicians as counseling progresses, and integrating follow-up into ongoing health care. ${ }^{16}$

Certain smoking cessation models provide an example of the use and integration of resources beyond the office. In some states and health systems, clinicians can identify smokers (assess) and offer brief advice (advise) in the office and then refer patients to telephone quit line programs that can offer more intensive counseling (assist, arrange). ${ }^{17}$ The best models, as in Massachusetts' quit line program, ${ }^{18}$ have a feedback component that enables counselors to share progress reports with the primary care clinician as part of a longitudinal team relationship. A research network projects.
Table 1. Interventions Evaluated in Prescription for Health Projects, by Counseling Step

\begin{tabular}{|c|c|c|c|}
\hline PBRN & $\begin{array}{l}\text { 1. Identify Behaviors } \\
\text { and Health Conditions } \\
\text { (Assess) }\end{array}$ & $\begin{array}{l}\text { 2. Brief Advicel } \\
\text { Training (Advise) }\end{array}$ & $\begin{array}{l}\text { 3. Goal Setting } \\
\text { (Agree) }\end{array}$ \\
\hline ACORN & Web-based behavior survey & $\begin{array}{l}\text { Brief Web-based counseling } \\
\text { message }\end{array}$ & \\
\hline APBRN & PDA screening; assess BMI & $\begin{array}{l}\text { PDA-guided advice to change } \\
\text { behavior }\end{array}$ & $\begin{array}{l}\text { PDA-guided goal } \\
\text { setting; action } \\
\text { plans }\end{array}$ \\
\hline $\mathrm{CECH}$ & PDA screening & & Action plans \\
\hline CRN & Health behavior survey & Menu for lifestyle change & Action plans \\
\hline COOP & $\begin{array}{l}\text { Vital sign questions from } \\
\text { medical assistants; } \\
\text { Web- and paper-based } \\
\text { health assessment }\end{array}$ & Brief advice & \\
\hline GRIN* & $\begin{array}{l}\text { Patient questionnaires; } \\
\text { nurse screening; BMI and } \\
\text { smoking status as vital } \\
\text { signs; } 5 \text { A's chart stickers; } \\
\text { healthy weight wall chart }\end{array}$ & $\begin{array}{l}\text { Brief advice by physician; brief } \\
\text { patient training by clinicians; } \\
\text { exercise prescription }\end{array}$ & Action plans \\
\hline $\begin{array}{l}\text { HPRN, } \\
\text { CaReNet }\end{array}$ & Intake survey & List of recommended behaviors & $\begin{array}{l}\text { Goals documented } \\
\text { on prescription } \\
\text { pads }\end{array}$ \\
\hline KAN & $\begin{array}{l}\text { "Willingness to change" } \\
\text { survey; physician query }\end{array}$ & Physician prescription/referral & \\
\hline MAFPRN & $\begin{array}{l}\text { Standardized screening for } \\
\text { tobacco use, physical activ- } \\
\text { ity, diet, risky drinking }\end{array}$ & $\begin{array}{l}\text { Brief motivational enhancement } \\
\text { by health coach }\end{array}$ & \\
\hline MNCCRN & $\begin{array}{l}\text { Assess diet, physical activity, } \\
\text { and BMI }\end{array}$ & $\begin{array}{l}\text { Participation in wellness club } \\
\text { recommended by advanced } \\
\text { practice nurse }\end{array}$ & $\begin{array}{l}\text { Weekly written } \\
\text { goals }\end{array}$ \\
\hline NECF & $\begin{array}{l}\text { Screening for tobacco use } \\
\text { and risky screening }\end{array}$ & $\begin{array}{l}\text { Brief motivational interviewing } \\
\text { by physician, nurse, physician } \\
\text { assistant, medical assistant, or } \\
\text { health educator }\end{array}$ & \\
\hline NOPCRN & $\begin{array}{l}\text { Assess BMI, nutrition, and } \\
\text { physical activity }\end{array}$ & $\begin{array}{l}\text { PDA-guided goal } \\
\text { recommendation }\end{array}$ & $\begin{array}{l}\text { PDA-guided goal } \\
\text { setting }\end{array}$ \\
\hline PitNet & $\begin{array}{l}\text { Assess BMI; parent percep- } \\
\text { tion survey }\end{array}$ & Brief motivational interviewing & \\
\hline PPRG & $\begin{array}{l}\text { Wall chart; nutrition } \\
\text { assessment }\end{array}$ & $\begin{array}{l}\text { Brief advice based on nutri- } \\
\text { tional status and menu for } \\
\text { lifestyle change }\end{array}$ & \\
\hline PSARN & Assess BMI & & \\
\hline RAP & & Prescription & \\
\hline VaPSRN & Smoking, BMI, vital signs & PDA tool to guide counseling & \\
\hline
\end{tabular}

Note: The contents of this table were reviewed and edited by investigators from each of the 17 Prescription for Health

*Interventions at GRIN practices varied and were determined and implemented individually by practices. in Virginia that was a grantee under Prescription for Health is now conducting a randomized trial, funded by the Agency for Healthcare Research and Quality, to test whether this integrated counseling model increases the quality of the assistance that smokers receive. ${ }^{19}$

A number of Prescription for Health projects pursued this approach, testing interventions that reached 


\section{More Intensive Assistance (Assist)}

$\begin{array}{llll}\text { Information } & \text { Counseling } & \text { Self-Management } & \text { 5. Reinforcement, } \\ \text { Follow-up (Arrange) }\end{array}$

Web database of community and behavior change resources Personalized handouts

Health change facilitator

Stage-based counseling

Web site information tailored to patient responses

Stage-tailored and need-specific educational materials, lists of local resources
Individual counseling, group visits, and referral to community services

Referral to community services
Self-management supported by automatic feedback to patient feedback to clinician, and Webbased problem-solving module Quit kits; community services
Telephone follow-up by practice extender

E-mail follow-up by health advisor based on action plan

Telephone call 1 wk and 6 mo later

Telephone/e-mail follow-up by RNs; follow-up visits as indicated by responses to vital sign process or feedback from Web health assessment

Telephone follow-up by nurses or community service

Feedback logs

$\begin{array}{cc}\text { Mailed educational materials } & \begin{array}{c}\text { Scheduled longitudinal tele- } \\ \text { phone counseling } \\ \text { Telephone or Web-based } \\ \text { motivational counseling } \\ \text { information }\end{array} \\ \begin{array}{c}\text { Written lesson plans for didactic } \\ \text { sessions }\end{array} & \begin{array}{c}\text { Support group; nutrition- } \\ \text { ist-led didactic sessions; } \\ \text { motivational videos }\end{array}\end{array}$

Literature

$$
\text { motivational videos }
$$

Faxed feedback to referring physician
Self-help guidebook; Web site; community resources and programs
Food diaries; pedometer counts

Telephone and e-mail follow-up by clinics; follow-up visits

Telephone follow-up by educator; health buddies; community activities (see Table 2)

Follow-up visit

\section{Pedometer; activity log}

Self-monitoring books sions

Health change facilitator; decision balance exercise; other motivational techniques
Self-help guidebook
Telephone follow-up by nurse-coordinator; biweekly nurse practice visits for weight and BP checks, pedometer downloads, and activity log assessment

Telephone follow-up

Health change facilitator follow-up in person, by telephone, by e-mail

Web database of community and behavior change resources

Patient resources suggested by PDA software

5 A's = assess, advise, agree, assist, arrange; ACORN = Virginia Ambulatory Care Outcomes Research Network; APBRN = Alabama Practice Based Research Network; BMI = body mass index; BP = blood pressure; CaReNet = Colorado Research Network; CECH = Center to Enhance Child Health Network; CRN = University of California at San Francisco (UCSF)/Stanford Collaborative Research Network; COOP = Dartmouth-Northern New England COOP Project; GRIN = Great Lakes Research Into Practice Network; HPRN = High Plains Research Network; KAN = Kentucky Ambulatory Network; MAFPRN = Minnesota Academy of Family Physicians Research Network; MNCCRN $=$ Midwest Nursing Centers Consortium Research Network; NECF = New England Clinicians Forum Practice-Based Research Network; NOPCRN = Northwest Ohio Primary Care Research Network; PBRN = practice-based research network; PDA = personal digital assistant; PitNet = Pediatric PitNet; PPRG = Pediatric Practice Research Group; PSARN = Pennsylvania State Ambulatory Research Network; RAP = Research Association of Practices; RN = registered nurse; VaPSRN = Virginia Practice Support and Research Network.

beyond the office to enable patients to access information at home (eg, through interactive Web sites), to use self-help methods (eg, guidebooks), to access intensive counseling after leaving the clinic (eg, intensive inperson or telephone sessions with trained counselors in the practice or through community health alliances) ${ }^{20}$ and to obtain follow-up and reinforcement over time (eg, health buddies, telephone or e-mail follow-up). ${ }^{4}$ Almost every project provided patients with resources that they could use at home to act on the advice they received in the office (Table 2). That so many grantees turned to this approach reflects not only the logic of leveraging, but also a recognition of the impracticality of the alternative: expecting practices to rely on their 
Figure 1. Integrated model of interventions evaluated by Prescription for Health projects.

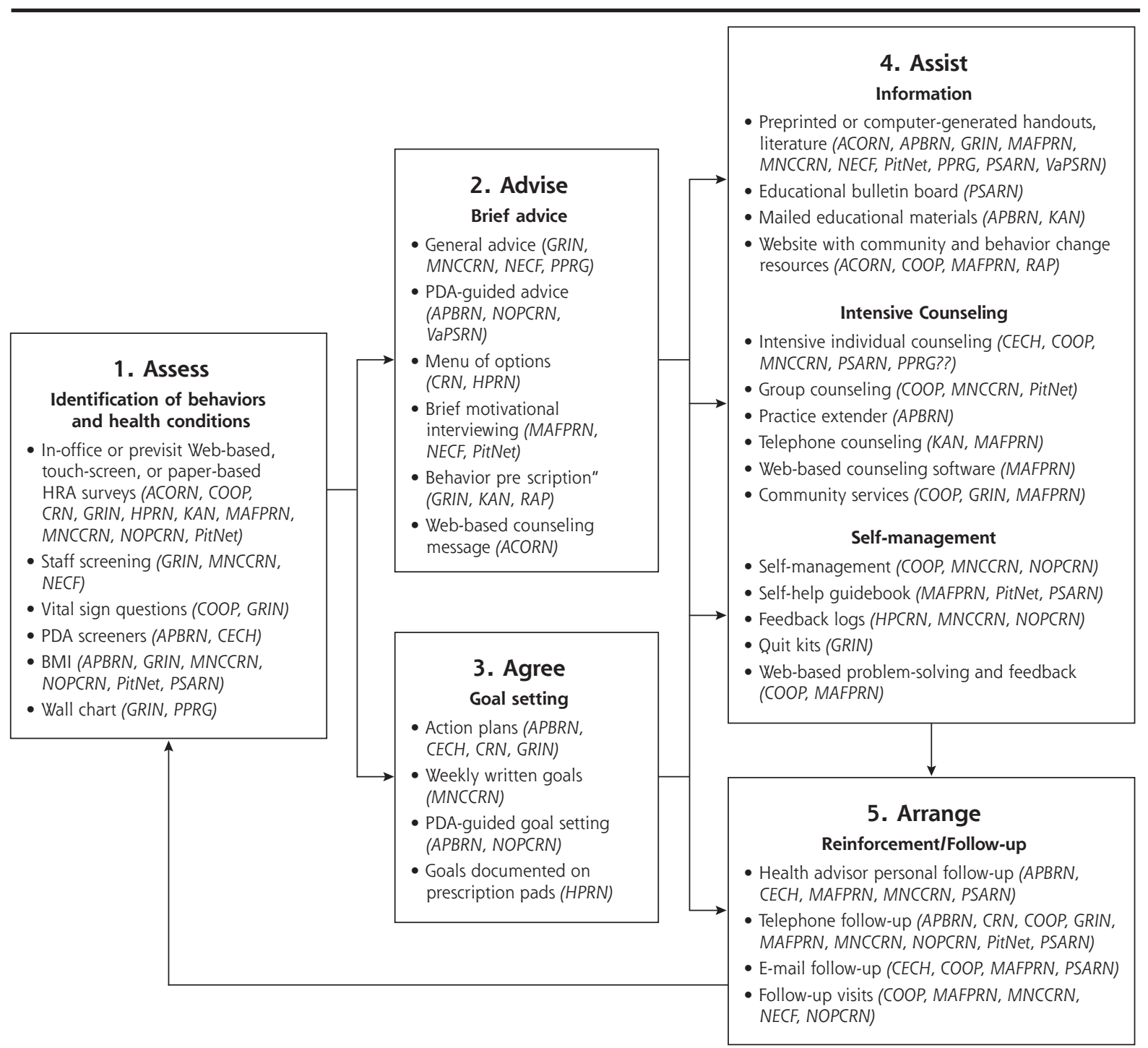

Note: See text for description of 5 A's (assess, advise, agree, assist, arrange). The practice-based research networks that evaluated the interventions are listed in parentheses. ACORN = Virginia Ambulatory Care Outcomes Research Network; APBRN = Alabama Practice Based Research Network; BMI = body mass index; CaReNet $=$ Colorado Research Network; CECH = Center for Enhanced Child Health Network; CRN = University of California at San Francisco (UCSF)/Stanford Collaborative Research Network: COOP $=$ Dartmouth-Northern New England COOP Project; GRIN = Great Lakes Research Into Practice Network; HRA = Health Risk Appraisal; HPRN = High Plains Research Network; KAN = Kentucky Ambulatory Network; MAFPRN = Minnesota Academy of Family Physicians Research Network; MNCCRN = Midwest Nursing Centers Consortium Research Network; NECF = New England Clinicians Forum Practice-Based Research Network; NOPCRN = Northwest Ohio Primary Care Research Network; PDA = personal digital assistant; PitNet $=$ Pediatric PitNet; PPRG $=$ Pediatric Practice Research Group; PSARN = Pennsylvania State Ambulatory Research Network; RAP $=$ Research Association of Practices; VaPSRN = Virginia Practice Support and Research Network.

own staff and resources to deliver intensive counseling and follow-up, often with limited or no reimbursement.

Aside from its pragmatic value to practices, this outreach is potentially more useful to patients because the work of lifestyle change occurs outside the clinic. An approach to health promotion that is restricted to the clinical encounter ignores the basic principles of the socioecological mode ${ }^{21}$ and compromises the effectiveness of health behavior counseling. Clinicians' time with patients represents a tiny fraction of patients' daily lives, and clinicians' efforts have limited impact on patients' health behaviors if conditions at home, at work, at school, and in the community are not supportive. ${ }^{4,22}$ Clinicians' influence on the lifestyle is possible through integrated and stable partnerships and linkages if an infrastructure is in place for these relationships to flourish.

\section{Parallels in Chronic Disease Management}

The same philosophy of integrated and comprehensive care is embedded in current thinking about how best to 
senior centers, news media, advertisers, urban planners, and the leaders who set direction for these sectors.

Community-level integration of this type is beginning to emerge in many communities, often through concerted efforts such as the Steps to a Healthier US Cooperative Agreement program. ${ }^{34}$ In 2004, this US Department of Health and Human Services program issued $\$ 36$ million in grants to 40 communities to develop integrated community action plans to reduce the burden of diabetes, overweight, obesity, and asthma, and to address risk factors such as physical inactivity, poor nutrition, and tobacco use. ${ }^{35}$

One Steps grantee (Seattle and King County, Wash), for example, has undertaken a comprehensive approach that involves media, policy makers, schools, workplaces, health care, and the community in a 100member consortium that includes clinicians, hospitals, health plans, universities, community organizations, faith groups, government agencies, and school districts. ${ }^{36}$ Their work with clinicians establishes integration between patient care and the community by using chronic disease and wellness coordinators to facilitate systems change, linking patients with community resources, and using case management. Their citizencentered approach takes integration to a much broader community level. Examples of their comprehensive efforts include promoting community and housing policies that support physical activity, discouraging sales of nonnutritious foods at schools, and working with faith communities to train lay educators in health promotion.

\section{The Challenges of Integrating Clinical and Community Services}

Integration makes sense but is hardly straightforward. Systems to help practices reach out beyond the office encounter logistical challenges, as Prescription for Health grantees discovered. Projects in Minnesota and Pennsylvania developed self-help materials but found that patients preferred telephone or face-to-face interpersonal contact. A Kentucky project found that only 500 of 15,000 patients who received postcard invitations to obtain telephone counseling called the program to arrange services. Projects in Virginia, Ohio, and Minnesota developed Web sites to facilitate behavior change but encountered technical challenges and low use rates. ${ }^{4}$ A New Hampshire project found that receiving e-mail messages was unpopular with adolescent patients. Projects using practice extenders required resources for training and efforts to maintain coordination with primary clinicians and to ensure privacy of data. ${ }^{4}$

Substantial resources are required to build an infrastructure within health care that integrates primary care practices and communities. The sources of funding to establish this infrastructure and their long-term sustain- ability are unclear. Tobacco quit lines, for example, have struggled as state budgets, a primary funding source, have tightened. ${ }^{37}$ For integration to be truly viable, these and other counseling resources to which clinicians might refer patients require stable funding; in addition, clinicians and health systems will expect reimbursement for the added work entailed in establishing and maintaining ties with diverse community services. ${ }^{38}$ Finally, the very definition of integration and the performance measures that evaluators would use to know when it exists require development.

\section{CONCLUSIONS}

The formidable challenges to integration must be overcome to make it a key feature of the future transformation of health care. Integration, the natural answer to the current fragmentation of health care, was highlighted by the Institute of Medicine as a national priority. ${ }^{39}$ The importance of integrating clinical and community services was evident in the Prescription for Health experience, but a similar lesson has been echoed in other quality improvement projects of the Robert Wood Johnson Foundation. Integration is a recurring theme in the foundation's work with other agencies (eg, the Institute for Healthcare Improvement, the MacColl Institute for Healthcare Innovation) and figures prominently in programs that bridge clinical practice and the community (eg, Pursuing Perfection, ${ }^{40}$ Improving Chronic Illness Care, ${ }^{41}$ Innovative Care for Chronic Conditions ${ }^{42}$ ) and that build partnerships between the community and public health agencies (eg, Turning Point ${ }^{43}$ ).

The prominence of integration and primary care in so many of these quality improvement programs underscores their vital role in drawing together the services that patients require to address their health needs. Over time, the premier quality improvement initiatives and accompanying research, including the second round of Prescription for Health, will clarify whether integration of services improves the health and satisfaction of the population. These insights might suggest solutions to the logistical barriers to implementing integration. Morbidity, mortality, and health care costs can be substantially reduced by even modest reductions in unhealthy behaviors. If the hard work of building a comprehensive system to support healthy lifestyles can make a difference, it is a cause well worth pursuing.

To read or post commentaries in response to this article, see it online at http://www.annfammed.org/cgi/content/full/3/Suppl_2/S20.

Key words: Integration; coordination; primary care; health promotion; health behavior; chronic disease; self-management; community services

Submitted January 18, 2005; submitted, revised, April 12, 2005; accepted April 19, 2005. 
Funding support: This work was supported by Prescription for Health (grant No. 049060), a national program of The Robert Wood Johnson Foundation with support from the Agency for Healthcare Research and Quality.

Acknowledgments: We thank investigators from the 17 Prescription for Health projects for reviewing the tables and figure in this manuscript, and we appreciate comments on the body of the text provided by Thomas Bodenheimer, MD; Myra A. Crawford, PhD, MPH; Cecelia A. Gaffney, MEd; Larry A. Green, MD; Anton J. Kuzel, MD, MS; Alfred F. Tallia, MD, $\mathrm{MPH}$; John H. Wasson, MD; and Diane B. Wilson, EdD, MS, RD. The comments of the anonymous reviewers were especially helpful.

\section{References}

1. Goldstein MG, Whitlock EP, DePue J. Multiple behavioral risk factor interventions in primary care: summary of research evidence. Am J Prev Med. 2004;27:61-79.

2. Whitlock EP, Orleans $C T$, Pender $N$, Allan J. Evaluating primary care behavioral counseling interventions: an evidence-based approach. Am J Prev Med. 2002;22:267-284

3. Glasgow RE, Goldstein MG, Ockene JK, Pronk NP. Translating what we have learned into practice: principles and hypotheses for interventions addressing multiple behaviors in primary care. Am J Prev Med. 2004;27:88-101.

4. Cohen DJ, Tallia AF, Crabtree BF, Young DM. Implementing health behavior change in primary care: lessons from Prescription for Health. Ann Fam Med. 2005;3(Suppl):S12-S19.

5. Mullen PD, Simons-Morton DG, Ramirez G, et al. A meta-analysis of trials evaluating patient education and counseling for three groups of preventive health behaviors. Patient Educ Couns. 1997;32:157-173.

6. Solberg LI, Brekke ML, Fazio CJ, et al. Lessons from experienced guideline implementers: attend to many factors and use multiple strategies. Jt Comm J Qual Improv. 2000;26:171-188.

7. The future of family medicine: a collaborative project of the family medicine community. Ann Fam Med. 2004;2(Suppl 1):S3-S32.

8. Institute of Medicine. Crossing the Quality Chasm: A New Health System for the 21st Century. Washington, DC: National Academies Press; 2001

9. Cifuentes M, Fernald DH, Green LA, Niebauer LJ, Crabtree BF, Hassmiller SB. Prescription for Health: changing primary care practice to foster healthy behaviors. Ann Fam Med. 2005;3(Suppl):S4-S12.

10. Dickey LL, Gemson DH, Carney P. Office system interventions supporting primary care-based health behavior change counseling. Am J Prev Med. 1999;17:299-308.

11. Glasgow RE, Bull SS, Piette JD, Steiner JF. Interactive behavior change technology: a partial solution to the competing demands of primary care. Am J Prev Med. 2004;27:80-87.

12. Bodenheimer T, Young DM, MacGregor K, Holtrop JS. Practice-based research in primary care: facilitator of or barrier to practice improvement? Ann Fam Med. 2005;3:p-p.

13. Kreuter MW, Chheda SG, Bull FC. How does physician advice influence patient behavior? Evidence for a priming effect. Arch Fam Med. 2000;9:426-433

14. Wasson JH, Godfrey MM, Nelson EC, Mohr JJ, Batalden PB. Microsystems in health care: Part 4. Planning patient-centered care. Jt Comm J Qual Saf. 2003;29:227-237.

15. Stange KC, Woolf SH, Gjeltema K. One minute for prevention: the power of leveraging to fulfill the promise of health behavior counseling. Am J Prev Med. 2002;22:320-323.

16. Peek CJ, Sanner B, Goldstein MG. Addressing Multiple Behavioral Risk Factors in Primary Care. West Haven, Conn: Bayer Institute for Health Care Communication; 2004

17. Centers for Disease Control and Prevention. Telephone Quitlines: A Resource for Development, Implementation, and Evaluation. Atlanta, Ga: Office on Smoking and Health, Centers for Disease Control and Prevention; 2004

18. Quitworks Web site. Available at: http://www.quitworks.org. Accessed December 31, 2004.
19. CRISP abstract, grant 1R21HS014854-01. Available at: http://crisp. cit.nih.gov/crisp/CRISP_LIB.getdoc?textkey $=6887120$ Ep_grant_ num = 1R21 HS014854-01Ep_query = Eticket = 12302004Ep_audit_ session_id $=58184385 \varepsilon$ p_keywords $=$. Accessed December 28, 2004.

20. Luce P, Phillips J, Benjamin R, Wasson JH. Technology for community health alliances. J Ambul Care Manage. 2004;27:366-374.

21. Cohen DA, Scribner RA, Farley TA. A structural model of health behavior: a pragmatic approach to explain and influence health behaviors at the population level. Prev Med. 2000;30:146-154.

22. Chin NP, Monroe A, Fiscella K. Social determinants of (un)healthy behaviors. Educ Health (Abingdon). 2000;13:317-328.

23. Bodenheimer T, Wagner EH, Grumbach K. Improving primary care for patients with chronic illness. JAMA. 2002;288:1775-1779.

24. Kaplan A. Curing the System: Stories of Change in Chronic Illness Care. Washington, DC: National Coalition on Health Care; 2002.

25. Wagner EH, Austin BT, Davis C, et al. Improving chronic illness care: translating evidence into action. Health Aff (Millwood). 2001;20:64-78.

26. Wagner $\mathrm{EH}$. The role of patient care teams in chronic disease management. BMJ. 2000;320:569-572.

27. Cherry JC, Dryden K, Kobb R, Hilsen P, Nedd N. Opening a window of opportunity through technology and coordination: a multisite case study. Telemed J E Health. 2003;9:265-271.

28. Glasgow RE, Nutting PA, King DK, et al. A practical randomized trial to improve diabetes care. J Gen Intern Med. 2004;19:1167-1174.

29. Glasgow RE, Orleans CT, Wagner EH. Does the Chronic Care Model serve also as a template for improving prevention? Milbank $Q$. 2001;79:579-612, iv-v.

30. Finlay SJ, Faulkner G. Physical activity promotion through the mass media: inception, production, transmission and consumption. Prev Med. 2005;40:121-130.

31. Welcome to VERB. Web site. Available at: http://www.cdc.gov/youthcampaign/index.htm. Accessed December 31, 2004.

32. Promoting Physical Activity in Communities: Forward-Looking Options From an Executive Roundtable. Washington, DC: Partnership for Prevention; 2002.

33. Jackson RJ. The impact of the built environment on health: an emerging field. Am J Public Health. 2003;93:1382-1384.

34. US Department of Health and Human Services. Steps to a HealthierUS Cooperative Agreement Program. Available at: http:// www. healthierus.gov/steps/grantees/StepsCoopAgrmnt_021804.pdf. Accessed December 31, 2004.

35. US Department of Health and Human Services. HHS awards $\$ 35.7$ million to support community programs that promote better health and prevent disease [press release]. September 28, 2004. Available at: http://www.hhs.gov/news/press/2004pres/20040928.html. Accessed December 31, 2004.

36. US Department of Health and Human Services. Steps to a HealthierUS: Seattle \& King County. 2004. Available at: http://www. healthierus.gov/ steps/grantees/Seattle.pdf. Accessed December 31, 2004.

37. Schroeder SA. Tobacco control in the wake of the 1998 master settlement agreement. N Engl J Med. 2004;350:293-301.

38. Bodenheimer T, Wang MC, Rundall TG, et al. What are the facilitators and barriers in physician organizations' use of care management processes? Jt Comm J Qual Saf. 2004;30:505-514.

39. Adams K, Corrigan JM, eds. Priority Areas for National Action: Transforming Health Care Quality. Washington, DC: National Academies Press; 2003.

40. Pursuing Perfection: Raising the Bar for Health Care Performance. Web site. Available at: http://www.ihi.org/lHI/Programs/PursuingPerfection. Accessed December 31, 2004.

41. About ICIC. Available at: http://www.improvingchroniccare.org/about/ index1.html. Accessed December 31, 2004.

42. Epping-Jordan JE, Pruitt SD, Bengoa R, Wagner EH. Improving the quality of health care for chronic conditions. Qual Saf Health Care. 2004;13:299-305.

43. Turning Point Performance Management National Excellence Collaborative. From Silos to Systems: Using Performance Management to Improve the Public's Health. Seattle, Wash: University of Washington; 2003. 